\title{
Urotensin II receptor as a potential biomarker for the prognosis of hepatocellular carcinoma patients
}

\author{
HONGTAO WEI ${ }^{1,2}$, XIAOTONG YU ${ }^{3}$, XIAOWEI XUE ${ }^{4}$, HUI LIU ${ }^{2}$, \\ MENGLONG WANG ${ }^{2}$, YINGYING $\mathrm{LI}^{3}$, XUEJIANG WANG ${ }^{3}$ and HUIGUO DING ${ }^{2}$
}

\author{
${ }^{1}$ Department of Emergency, Beijing Friendship Hospital, ${ }^{2}$ Department of Gastroenterology and Hepatology, \\ Beijing Youan Hospital, and ${ }^{3}$ Department of Physiology and Pathophysiology, School of Basic Medical Sciences, \\ Capital Medical University, Beijing 100069; ${ }^{4}$ Department of Pathology, Peking Union Medical College Hospital, \\ Chinese Academy of Medical Sciences, Beijing 100730, P.R. China
}

Received November 11, 2016; Accepted June 26, 2017

DOI: $10.3892 / \mathrm{ol} .2017 .6545$

\begin{abstract}
Urotensin II and the associated urotensin II receptor (UTR) are important in the carcinogenesis of hepatocellular carcinoma (HCC). However, the clinical significance of UTR remains to be elucidated. The aim of the present study was to investigate if UTR exhibits the potential to act as a biomarker to predict the prognosis of HCC patients. The effects of UTR on motility and invasion of HCC cells were additionally investigated. UTR expression levels were determined by immunohistochemistry, in $83 \mathrm{HCC}$ patients that previously underwent curative liver resection. The association between UTR levels and clinicopathological data were analyzed. In vitro, the expressions of UTR in QSG-7701, BEL-7402 and MHCC-97H cell lines were determined via western blotting. Small interfering (si)RNA was used to downregulate UTR in BEL-7402 and MHCC-97H cell lines, and the effects of UTR on tumor cell motility were tested by Transwell assay. UTR expression was associated with tumor number, size, histology and tumor node metastasis/Barcelona Clinic Liver Cancer HCC stage. UTR expression levels were additionally
\end{abstract}

Correspondence to: Professor Xuejiang Wang, Department of Physiology and Pathophysiology, School of Basic Medical Sciences, Capital Medical University, 10 Xitoutiao, Youanmenwai Street, Fengtai, Beijing 100069, P.R. China

E-mail: xjwang@ccmu.edu.cn

Professor Huiguo Ding, Department of Gastroenterology and Hepatology, Beijing Youan Hospital, Capital Medical University, 8 Xitoutiao, Youanmenwai Street, Fengtai, Beijing 100069, P.R. China E-mail: dinghuiguo@medmail.com.cn

Abbreviations: AFP, $\alpha$-fetoprotein; HCC, hepatocellular carcinoma; OS, overall survival; RFS, recurrence-free survival; UII, urotensin II; UTR, urotensin II receptor; IHC, Immunohistochemistry; siRNA, small interfering RNA

Key words: urotensin II receptor, hepatocellular carcinoma, motility, prognosis associated with recurrence-free and overall survival in HCC patients by Kaplan-Meier curve analysis $(\mathrm{P}<0.0001)$. In vitro, UTR expression levels were increased in BEL-7402 and MHCC-97H cell lines, compared with QSG-7701 $(\mathrm{P}<0.05)$. siRNA-mediated silencing of the UTR gene significantly inhibited cell motility in BEL-7402 and MHCC-97H cells. The results indicated that UTR may be regarded as a novel biomarker to predict outcomes following radical liver resection and as a potential therapeutic target to inhibit invasion and metastasis of HCC.

\section{Introduction}

Hepatocellular carcinoma (HCC) is the fifth most common malignancy and the third cause of tumor associated deaths worldwide (1). The curative therapies currently available for HCC are liver resection, local ablative treatments and liver transplantation (2). Due to limited donors, rigorous indication for local ablative treatments, liver tumor resection is the main curative treatment for HCC in clinical practices (3). However, the recurrence rate after hepatic resection was over $70 \%$ in 5 years (4). The high recurrence and metastasis are closely related to poor prognosis of HCC patients after radical treatment. Currently, there is no effective way to radically prevent recurrence and metastasis of HCC. Therefore, it is of great clinical significance to accurately determine the prognosis and take the corresponding individualized treatment after surgery, which will be helpful to improve the long-term survival of HCC patients.

Human urotensin II (UII), isolated from the urophysis of teleost fish, is an undecapeptide (H-Glu-Thr-Pro-Asp-c [Cys-Phe-Trp-Lys-Tyr-Cys]-Val-OH). The orphan G-protein coupled receptor 14 was identified as the urotensin II receptor (UTR) (5). As a powerful vasoactive peptide in mammals, initially UII/UTR is reported to play an important role in portal hypertension, renal disease and heart failure (5). Recent studies demonstrated that UII/UTR may involve in tumorigenesis and tumor progression in many malignant tumors (6), such as adrenal gland neoplasms (7), breast carcinoma (8), pulmonary adenocarcinoma (9), renal cell carcinoma and colon carcinoma (10). Our previous study demonstrated that UII 
and UTR are up-regulated in rat HCC model and human HCC tissue, exogenous UII can increase hepatic oval cell and HCC cell proliferation in vitro (11-13). All these results indicated that UII played an important role in initiation and progression of HCC. And in our preliminary experiment, we also found that the intensity of UTR expression on HCC tissues varies from patient to patient. So, we wonder whether UTR has a clinical significance in HCC patients and whether UTR plays a role on HCC development.

The aim, in the present study, was to determine whether UTR could be as a biomarker to predict the outcomes of HCC patients underwent radical treatment. The effects of UTR on HCC cell motility and invasion was also explored.

\section{Materials and methods}

Patients and tissue samples. HCC patients underwent curative resection at Beijing Youan Hospital (Beijing, China) from January 2010 to March 2013 were enrolled. Patients had a history of malignancy, or previous anticancer therapy, or detectable distant metastases, or carrying tumor residual after surgery, or received special treatment (such as gene therapy, molecular targeted drug therapy) during follow-up, were excluded from the present study. HCC were staged according to the TNM staging system of the Union for International Cancer Control/American Joint Committee on Cancer (AJCC, 7thedition), and Barcelona Clinic Liver Cancer (BCLC) staging system. The clinicopathological characteristics of patients were retrieved from the medical records and summarized in Table I. The study was approved by the Ethics Committee of Beijing Youan Hospital, Capital Medical University. Written informed consent was obtained from each patient.

Follow-up and endpoints. All enrolled patients were follow-up in real-life clinical practice by outpatient clinic or telephone. The primary endpoints were death or 3 years (36 months) follow-up, and the secondary endpoint was HCC recurrence.

In total, $14(16.87 \%)$ patients were lost to follow-up. Forty patients (48.19\%) recurrence and 18 patients (21.69\%) death were observed during 3 years follow-up.

Immunohistochemistry (IHC). Formalin-fixed, paraffinembedded HCC tissues samples were collected from the 83 patients above-mentioned. The immunohistostaining (IHS) was routinely done. In briefly, the sections were incubated with a specific antibody against UTR 1:200 [GPR14 (M-250): sc-28998; Santa Cruz Biotechnology, Inc., Santa Cruz, CA, USA] at $4^{\circ} \mathrm{C}$ for overnight and then incubated with a second antibody with broad spectrum (Invitrogen, Carlsbad, CA, USA) at $37^{\circ} \mathrm{C}$ for $20 \mathrm{~min}$. After washed by PBS for three times, the visualization signal was used by a 3,3'-diaminobenzidine and counterstained with hematoxylin. The result of IHS was separately determined by two experienced pathologists. UTR scores were determined by assessing both staining intensity and the proportion of positively stained tumor cells. IHS intensity was divided into 0 , no positive staining; 1 , positive staining was weak yellow; 2 , positive staining was yellow and 3 , strong positive staining was brown. The mean percentage of positive tumor cells was determined in five fields under $\mathrm{x} 400$ magnification. UTR positive expression was estimated as staining intensity $\mathrm{x}$ mean percentage of positive tumor cells. The scores $\leq 4$ was regarded as UTR low expressions and 5-12 as UTR high expressions.

Western blot analysis. The UTR protein concentration was determined using a BCA protein assay kit (Thermo Fisher Scientific, Waltham, MA, USA) as described in the manufacturer's manual. Lysate protein $(80 \mu \mathrm{g})$ was separated on $10 \%$ SDS-PAGE gels and transferred to a polyvinylidene fluoride membrane. After blotting, the membrane was blocked in 5\% skim milk in TBST for $1 \mathrm{~h}$ at room temperature and then incubated with the specific primary antibody against UTR $(1: 500)$ and GAPDH $(1: 5,000)$ at $4^{\circ} \mathrm{C}$ overnight. After well washed by TBST, membranes were then incubated with horseradish perxoidase-conjugated secondary antibody $(1: 5,000)$. The membrane was developed by enhanced chemiluminescence detecting reagents. And densities of specific proteins were normalized according to the amount of total protein and GAPDH.

Cell lines. Human hepatic cell line QSG-7701, human HCC cell line BEL-7402 (obtained from the Cell Bank of the Chinese Academy of Sciences, Shanghai, China), and MHCC-97H cells (human HCC cell lines with high metastatic potential, established at the Liver Cancer Institute, Zhongshan Hospital, Fudan University, Shanghai, China) were maintained in Dulbecco's modified Eagle's medium containing $10 \%$ of fetal calf serum and antibiotics (100 U/ml penicillin and $100 \mu \mathrm{g} / \mathrm{ml}$ streptomycin). The cells were harvested in the logarithmic phase of growth and serum-starved for $8 \mathrm{~h}$ before used in experiments outlined below.

Small interfering RNA-mediated UTR gene silencing. The expression of human UTR was knocked down using small interfering RNA (siRNA) duplexes (two sequences and one control siRNA). The two pre-designed siRNA (1-sense, 5'CCA UGUACGUCUACGUGGUTRT-3' and antisense, 5'-ACCACG UAGACGUACAUGGAG-3'; 2-sense, 5'ACGCAACCCUCA ACAGCUCtt-3' and antisense, 5'-GAGCUGUUGAGGGU UGCGUtg-3') were bought from Life Technologies Corp., (Carlsbad, CA, USA). Fluorescein Conjugate (A: sc-36869, Santa Cruz Biotechnology, Inc.) was used as control. Cells $\left(10^{5}\right)$ in the exponential growth phase were inoculated in 6-well plates and cultured for $24 \mathrm{~h}$. According to the manufacturer's recommended protocol, cells were serum-starved for $8 \mathrm{~h}$ before transfected with $10 \mu \mathrm{M}$ siRNA in serum free medium (Opti-MEM; Gibco, Grand Island, NY, USA). The result of transfection was analyzed by western blot analysis.

In vitro invasion and motility assays. Transfected cells $\left(2 \times 10^{4}\right)$ in $200 \mu 1$ serum free medium were added to the upper compartment of MilliCell (12 mm diameter with $8 \mu \mathrm{m}$ pores) chambers which were pre-coated with Matrigel (Corning Inc., Corning, NY, USA), and the chambers were placed into 24-well plates with $0.5 \mathrm{ml}$ complete medium. After $24 \mathrm{~h}$ cultivation at $37^{\circ} \mathrm{C}$, chambers were taken out and washed with PBS (5 times, each for $5 \mathrm{~min}$ ) after the medium was discarded. Immediately, the chambers were fixed in 24-well plates with $1 \mathrm{ml}$ absolute ethyl alcohol for $15 \mathrm{~min}$. washed with PBS for 3 times, the chambers were then stained with $1 \mathrm{ml}$ crystal violet $(0.1 \%)$ for another 
Table I. Correlation between UTR expressions and clinicopathologic variables of patients with HCC.

\begin{tabular}{|c|c|c|c|c|}
\hline \multirow[b]{2}{*}{ Variables } & \multirow[b]{2}{*}{ Total $(n=83)$} & \multicolumn{2}{|c|}{ Expression of UTR } & \multirow[b]{2}{*}{ P-value } \\
\hline & & Low $(n=44)$ & High $(n=39)$ & \\
\hline $\operatorname{Sex}(\%)$ & & & & 0.948 \\
\hline Male & $70(84.34)$ & $37(84.09)$ & $33(84.62)$ & \\
\hline Female & $13(15.66)$ & $7(15.91)$ & $6(15.38)$ & \\
\hline Age (years) (\%) & & & & 0.089 \\
\hline$\leq 50$ & $45(54.22)$ & $20(45.45)$ & $25(64.10)$ & \\
\hline$>50$ & $38(45.78)$ & $24(54.55)$ & $14(35.90)$ & \\
\hline Underlying liver disease (\%) & & & & 0.432 \\
\hline $\mathrm{HBV}$ & $76(91.57)$ & $39(88.64)$ & $37(94.87)$ & \\
\hline $\mathrm{HCV}$ & $5(6.02)$ & $4(9.09)$ & $1(2.56)$ & \\
\hline Others & $2(2.41)$ & $1(2.27)$ & $1(2.56)$ & \\
\hline Tumor location (\%) & & & & 0.271 \\
\hline Right lobe & $61(73.49)$ & $32(72.73)$ & $29(74.36)$ & \\
\hline Left lobe & $16(19.28)$ & $9(20.45)$ & $7(17.95)$ & \\
\hline Bilateral & $4(4.82)$ & $1(2.27)$ & $3(7.69)$ & \\
\hline Caudate & $2(2.41)$ & $2(4.55)$ & $0(0)$ & \\
\hline Tumor number $(\%)$ & & & & $0.002^{\mathrm{b}}$ \\
\hline Single & $60(72.29)$ & $38(86.36)$ & $22(56.41)$ & \\
\hline Multiple & $23(29.71)$ & $6(13.64)$ & $17(43.59)$ & \\
\hline Tumor size (cm) & & & & $0.017^{\mathrm{b}}$ \\
\hline$<3$ & $30(36.14)$ & $22(50.00)$ & $8(20.51)$ & \\
\hline $3-5$ & $31(37.35)$ & $14(31.82)$ & $17(43.59)$ & \\
\hline$>5$ & $22(26.51)$ & $8(18.18)$ & $14(35.90)$ & \\
\hline $\operatorname{AFP}(\mathrm{ng} / \mathrm{ml})(\%)$ & & & & 0.296 \\
\hline$<20$ & $36(43.37)$ & $21(47.73)$ & $15(38.46)$ & \\
\hline $20-400$ & $22(26.51)$ & $13(29.55)$ & $9(23.08)$ & \\
\hline$>400$ & $25(30.12)$ & $10(22.73)$ & $15(38.46)$ & \\
\hline TNM stage (\%) & & & & $0.000^{\mathrm{b}}$ \\
\hline $\mathrm{I}+\mathrm{II}$ & $57(68.67)$ & $41(93.18)$ & $16(41.03)$ & \\
\hline III+IV & $26(31.33)$ & $3(6.82)$ & $23(58.97)$ & \\
\hline BCLC HCC stage (\%) & & & & $0.000^{\mathrm{b}}$ \\
\hline A & $42(50.60)$ & $30(68.18)$ & $12(30.77)$ & \\
\hline B & $22(26.51)$ & $12(27.27)$ & $10(25.64)$ & \\
\hline $\mathrm{C}$ & $19(22.89)$ & $2(4.55)$ & $17(43.59)$ & \\
\hline Child-Pugh class $(\%)$ & & & & 0.139 \\
\hline A & $75(90.36)$ & $42(95.45)$ & $33(84.62)$ & \\
\hline B & $8(9.64)$ & $2(4.55)$ & $6(15.38)$ & \\
\hline Histologic grade $(\%)$ & & & & $0.021^{\mathrm{b}}$ \\
\hline Poorly & $18(21.69)$ & $5(11.36)$ & $13(33.33)$ & \\
\hline Moderate & $52(62.65)$ & $29(65.91)$ & $23(58.97)$ & \\
\hline Well & $13(15.66)$ & $10(22.73)$ & $3(7.69)$ & \\
\hline Tumor recurrence $(\%)$ & & & & $0.000^{\mathrm{b}}$ \\
\hline No & $43(51.81)$ & $31(74.45)$ & $12(30.77)$ & \\
\hline Yes & $40(48.19)$ & $13(29.55)$ & $27(69.23)$ & \\
\hline Mortality (\%) & & & & $0.000^{\mathrm{b}}$ \\
\hline No & $65(78.31)$ & $41(93.18)$ & $24(61.54)$ & \\
\hline Yes & $18(21.69)$ & $3(6.82)$ & $15(38.46)$ & \\
\hline
\end{tabular}

${ }^{a} \mathrm{P}$-value comparison between lower UTR expression and higher UTR expression; ${ }^{\mathrm{b}} \mathrm{P}<0.05$. UTR, urotensin II receptor; HCC, hepatocellular carcinoma; HBV, hepatitis B; HCV, hepatitis C; AFP, $\alpha$-fetoprotein; BCLC, Barcelona Clinic Liver Cancer. 


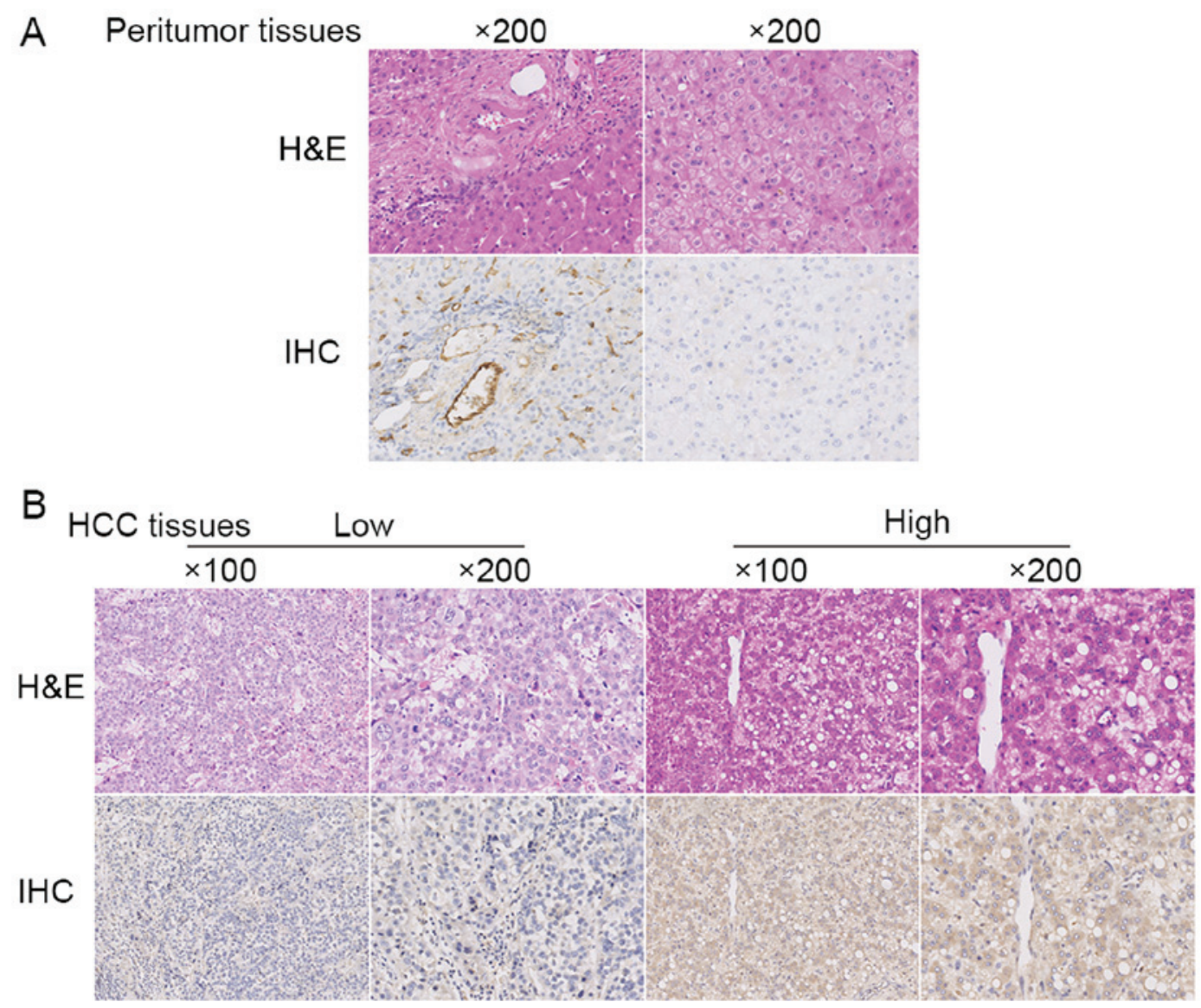

Figure 1. UTR expressions in (A) peritumor and (B) HCC tissues. UTR, urotensin II receptor; HCC, hepatocellular carcinoma; H\&E, hematoxylin and eosin staining; IHC, immunohistochemistry; low, low UTR expression; high, high UTR expression.

15 min. Cells were well washed with PBS buffer. Then cells in the upper compartment of chambers were wiped away, and which in the lower compartment of chambers were observed by light microscope. The amount of five high power fields per chamber were counted and mean value was calculated. The invasive activity was quantified from at least three individual chambers. The migration assay is similarly performed using invasion assay excepting that no Matrigel was used.

Statistical analysis. Data were analyzed with SPSS Statistics software, version 22.0 (IBM Corporation, Armonk, NY, USA). Differences among the categorical variables and quantitative variables were analyzed using Chi-square and the paired Wilcoxon signed rank test/unpaired t-test, respectively. Univariate and multivariate Cox proportional hazards analyses were used to assess the effects of various factors on prognosis. Kaplan-Meier analysis was used to assess recurrence-free survival (RFS)/overall survival (OS), and log-rank tests were used to compare them between the subgroups. All P-values were two-sided, and $\mathrm{P}<0.05$ was considered to be statistically significant.

\section{Results}

The clinical characteristics of enrolling patients. In a total of 83 enrolled HCC patients, $77(92.77 \%)$ patients underwent lobectomy and $8(7.23 \%)$ patients underwent hemihepatectomy. There were 70 men and 13 women $(84.34 \%$ vs. $15.66 \%)$.
The age of 45 (54.22\%) patients were under 50 years. A total of $76(91.57 \%)$ patients had chronic hepatitis B, and $5(6.02 \%)$ had chronic hepatitis C. Majority (73.49\%) of the tumor was located at right lobe. A total of $23(29.71 \%)$ patients had more than one tumor in their liver. The tumor sizes in $30(36.14 \%)$ patients were no more than $3 \mathrm{~cm}$, while in $22(26.51 \%)$ patients were more than $5 \mathrm{~cm}$. Serum $\alpha$-fetoprotein (AFP) levels in $36(43.37 \%$ ) patients were less than $20 \mathrm{ng} / \mathrm{ml}$, that in $22(26.51 \%)$ patients range between 20 to $400 \mathrm{ng} / \mathrm{ml}$, and in 25 (30.12\%) patients were above $400 \mathrm{ng} / \mathrm{ml}$. According to TNM stage classification, $57(68.67 \%)$ patients were I or II stage. While according to BCLC staging, 42 (50.60\%) patients were stage A, 22 (26.51\%) stage B, 19 (22.89\%) stage C. Poor differentiation was found in $18(21.69 \%)$ patients, and moderate differentiation was found in $52(62.65 \%)$ patients, and well differentiation was found in $13(15.66 \%)$ patients.

UTR expression characteristic on tissues. In the peritumor tissues, UTR staining was positive in the vessels and portal area, and the little staining or negative in the normal liver cells (Fig. 1A). Whereas in HCC tissues, UTR staining was detected positive in the cytomembrane and cytoplasm of HCC cells (Fig. 1B).

Relationship between expressions of UTR and clinicopathological characteristics. Based on UTR expressions determined by IHC, the HCC patients were divided into two subgroups: low UTR expressions group ( $\mathrm{N}=44)$ and high UTR expressions 

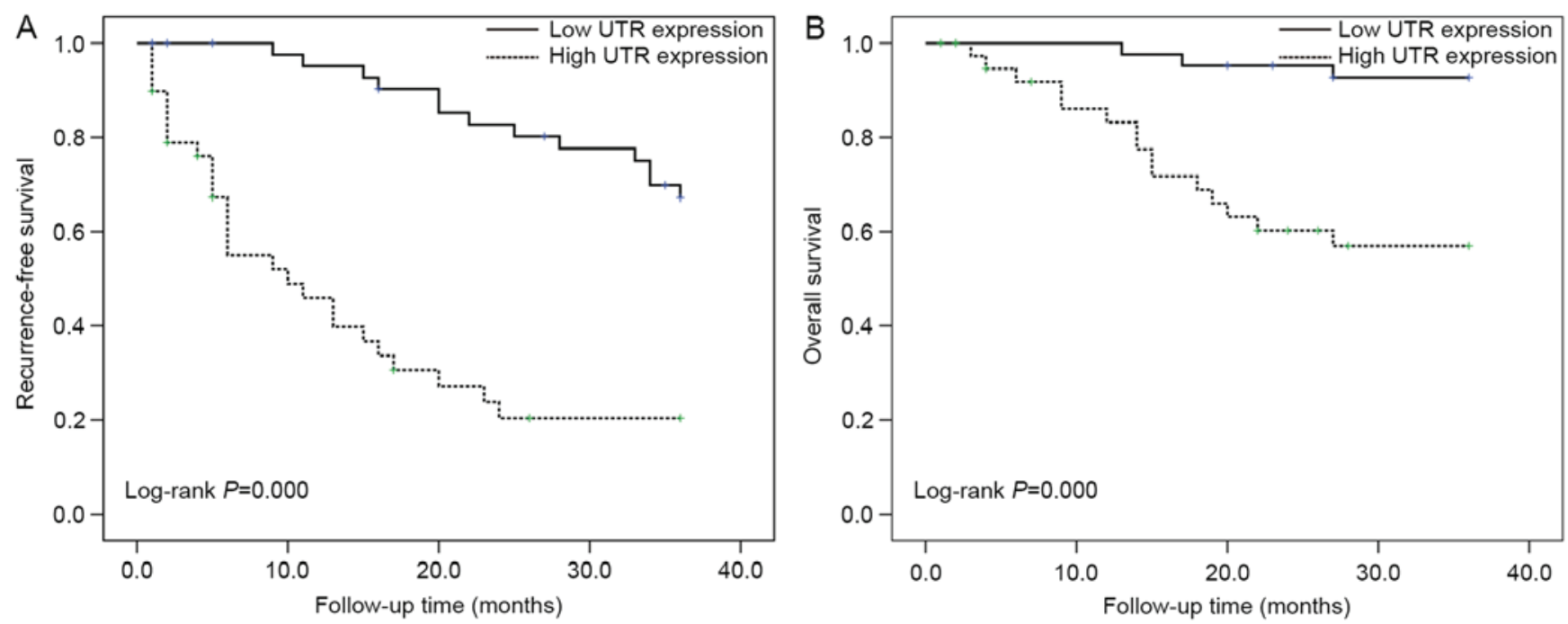

Figure 2. The relationship between UTR expression and survival. Kaplan-Meier curve for (A) recurrence-free survival and (B) overall survival for the low and high expression of UTR patients with hepatocellular carcinoma. UTR, urotensin II receptor.

group $(\mathrm{N}=39)$. The clinicopathological characteristics between the two subgroups were shown in Table I. Those with high expression levels of UTR had higher stage of HCC progression, such as higher TNM stage and BCLC stage ( $\mathrm{P}=0.000, \mathrm{P}=0.000)$, more multiple tumor, bigger tumor size, poorer histologic grade, high tumor recurrence and mortality $(\mathrm{P}=0.004,0.026$, $0.021,0.000$ and 0.000 , respectively). There were no correlation between UTR expressions and sex, age, chronic liver disease, tumor location, serum AFP, and Child-Pugh class ( $\mathrm{P}>0.05)$.

RFS and OS. The relationship between RFS/OS and UTR expressions were summarized in Table II. Three parameters including tumor number $(\mathrm{P}=0.009)$, TNM stage $(\mathrm{P}=0.000)$, and high expression of UTR $(\mathrm{P}=0.000)$ were significantly related to RFS. The TNM stage, Child-pugh class and UTR high expressions $(\mathrm{P}=0.002, \mathrm{P}=0.013$ and $\mathrm{P}=0.001)$ were also significantly related to OS. It found that UTR high expressions were an independent prognostic factor for RFS and OS ( $\mathrm{P}=0.004$ and 0.038 , respectively). The Kaplan-Meier curve and log-rank test also indicated that UTR expressions was associated with RFS and OS in HCC patients $(\mathrm{P}=0.000$ and $\mathrm{P}=0.000$; Fig. $2 \mathrm{~A}$ and $\mathrm{B}$ ).

siRNA-mediated UTR gene silencing. First, we determined the expression of UTR in two HCC cell lines and one normal cell line using western blot analysis. We found higher UTR expressions in the HCC cell lines (BEL-7402 and MHCC-97H) than in normal cell lines (QSG-7701) (Fig. 3A). Then, we knocked down UTR gene using two defined siRNAs (methods above-mentioned) in BEL-7402 and MHCC-97H cells, respectively. The level of UTR protein, normalized by GAPDH was obviously reduced compared with that in the negative control cells (Fig. 3B). Furthermore, Transwell invasion assays revealed that silencing UTR expression decreased the invasion of the BEL-7402 and MHCC-97H cells compared to the control cells $(\mathrm{P}<0.05$; Fig. 3C). Silencing UTR expression was also decreased the migration of HCC cells $(\mathrm{P}<0.05$; Fig. 3D). These results indicated the positive role of UTR in migration and invasion of human HCC cell lines in vitro.

\section{Discussion}

Our study shows that UTR is the potential biomarker to predict the prognosis in HCC patients after radical liver resection, and patient with a higher expression of UTR always has a worse prognosis than that with a lower expression of UTR. The evidence are as follows: Firstly, we demonstrate that UTR expression was associated with HCC malignant features, such as HCC stage, tumor number and tumor size; secondly, patients with a higher UTR expression level tend towards a high recurrence and mortality rate after resection, and survival curves (RFS and OS) showed significant difference between the two subgroups; finally, univariate and multivariate analysis found that UTR was an independent risk factor for predicting RFS and OS. In the light of these results, we suggest those patients with high UTR expression should be closely monitored or taken prophylactic treatments, such as molecular targeted drug therapy.

In several other malignancies, upregulation of UTR has been observed to have a relationship with poor prognosis (6). Federico et al (10) reported that UTR may play a role in colon carcinogenesis, when they found that UTR is expressed at a higher positive rate in colon adenocarcinomas than in adenomatous polyps and normal epithelial cells (65-90, 30-48 and 5-30\%, respectively). De Cobelli et al (14) and Grieco et al (15) suggested that UTR could be considered as prognostic marker in human prostate carcinoma patients. Franco et al (16) reported that UTR expression determines prognosis of bladder cancer, through discriminating non-muscle-invasive bladder transitional cancer (NMIBC) from muscle-invasive bladder transitional cancer and predicting the risk of relapses in NMIBCs. Consistent with these findings, we found that high UTR expression level was associated with poor prognosis in HCC patients after radical liver resection.

Migration and invasion are the embodiment of tumor metastasis ability. Evidence shows that tumor metastasis occurs at an early stage (17-19), and suggests that early metastasis is one of the major causes of recurrence and poor prognosis after 


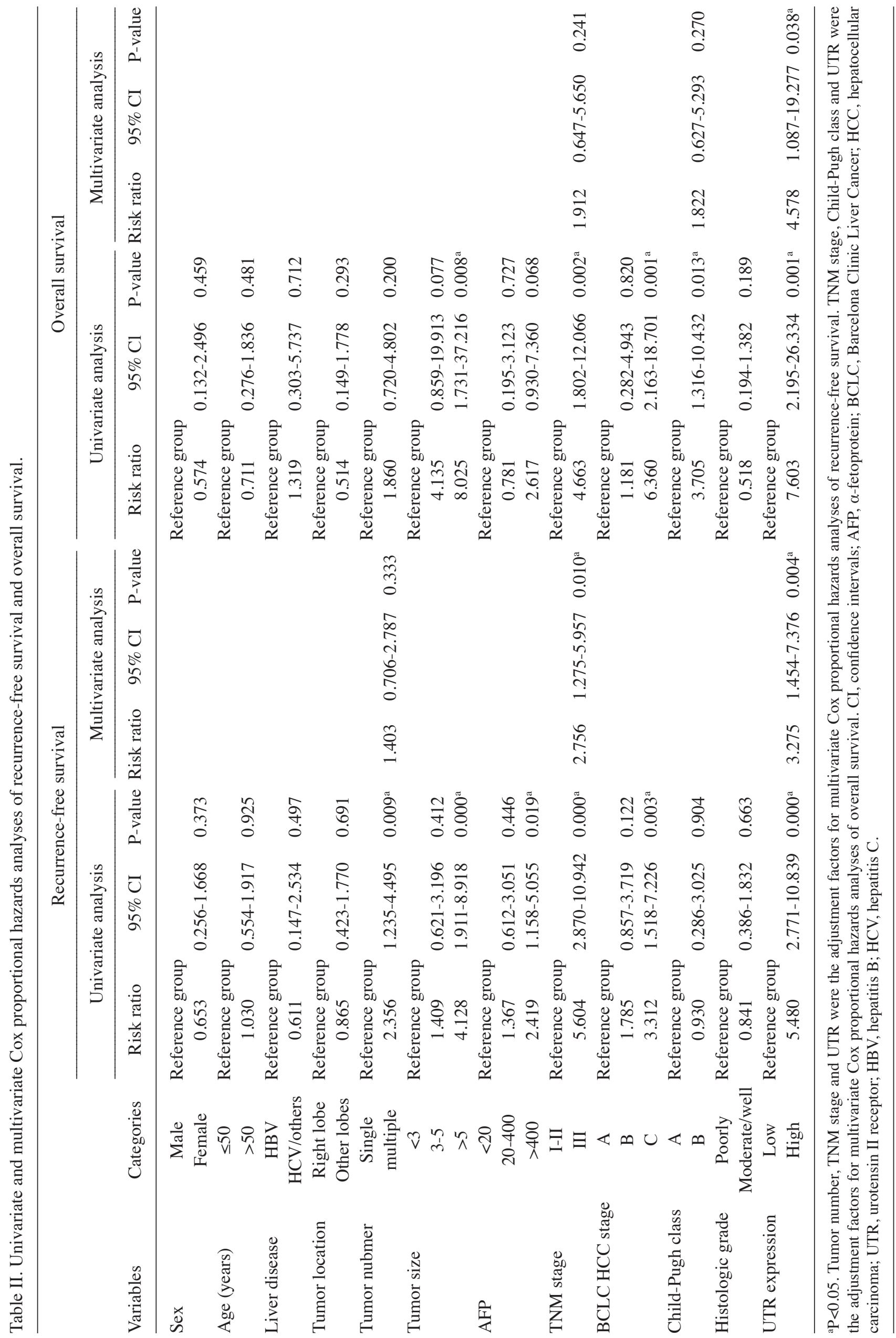



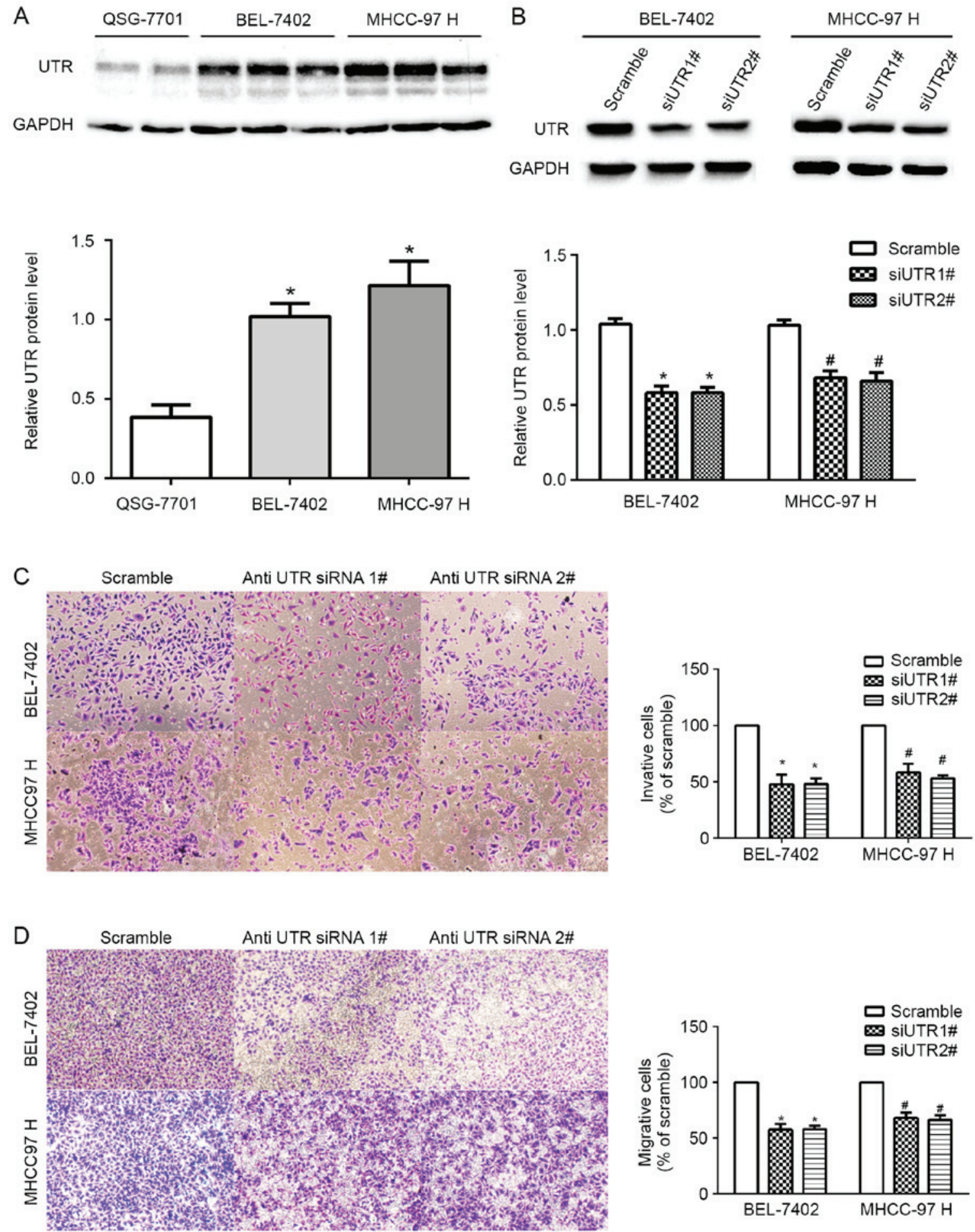

Figure 3. UTR-gene-silencing inhibits HCC cell migration and invasion. (A) UTR high expressions in BEL-7402, MHCC-97H compared with QSG-7701. (B) UTR expression decreased in BEL-7402, MHCC-97H transfected with siRNA compared with control vector. UTR protein was measured using western blot analysis. The data was expressed as mean $\pm \mathrm{SD}$. " $\mathrm{P}<0.05$; ${ }^{\#} \mathrm{P}<0.05$ vs. QSG-7701 (in A) and scramble (in B-D). (C) Invasion and (D) migration measured by Transwell assays was weakened in both HCC cell lines treated by siRNA. UTR, urotensin II receptor; HCC, hepatocellular carcinoma.

surgical resection (20). Moreover, several studies have reported that UTR can stimulate the migration and invasion of many malignant cell lines. For example, it is reported that UTR is involved in the regulation of motility and invasion of colon cancer (10), bladder cancer cells (16) and prostate adenocarcinoma cells (15). Furthermore, we found a positive correlation between UTR expression and HCC cells metastatic potential (UTR levels, MHCC-97H > BEL-7402 >> QSG-7701) in vitro study. Therefore, we speculate UTR may mediate cell invasion and migration in HCC cells. In order to investigate our speculation, we used two siRNAs to downregulate UTR level and then monitored cell motility behavior in vitro. Consistent with our speculation, the results showed that UTR knockdown in HCC cells reduced migration and invasion. Our results are complementary to our previous studies, in which UII/UTR system is found expressing differences between tumor and peri-tumor, 
and promoting tumorigenesis in hepatic progenitor cell (9). These studies together suggest UTR as a target for future HCC therapies because it plays an important role in tumorigenesis and tumor progression.

In our study, information of the caval/portal thrombosis during the follow-up were not included. It would be better to correlate them to UTR expression at the moment of the HCC recurrence. In clinical practice, it is difficult to evaluate wheather or not caval/portal thrombosis exist, especially in patients followed-up by telephone, without obtaining all-around medical information. And in future study, it is possible to carry out the correlation between UTR and caval/portal thrombosis in selected patients with good compliance.

The drawbacks of this study cannot be ignored. Due to small sample size and retrospective study, a more comprehensive analysis was not done for the risk factors determining poor OS and RFS, such as platelet count, microscopic vascular invasion, anatomic resection, grade of inflammation and antiviral therapy.

In conclusion, our novelty findings indicate that UTR may be regarded as a novel biomarker to predict outcomes after radical liver resection. It is also suggested that UTR as a potential therapeutic target inhibited invasion and metastasis of HCC.

Poor prognosis of hepatocellular carcinoma (HCC) patients is closely related to high recurrence, invasion and metastasis after radical treatment. In this study, we reported some novelty findings that urotensin II receptor (UTR) overexpression was associated with tumor number and size, histology, TNM/BCLC HCC stage, recurrence and mortality, and also correlated with recurrence-free survival and overall survival in HCC patients underwent curative liver resection. Furthermore, siRNA-mediated silencing UTR expression inhibited HCC cell motility and Invasion. Our novelty findings indicate that UTR may be regarded as a novel biomarker to predict outcomes after radical liver resection and as a potential therapeutic target for HCC.

\section{Acknowledgements}

This study was supported by grants from National Natural Science Foundation of China (grant no. 81272757 and 81672725), the Project of Construction of Innovative Teams and Teacher Career Development for Universities and Colleges under Beijing Municipality (grant no. IDHT20150502), the Capital Science and Technology Development Fund (2014-1-2181), Beijing Municipal Administration of Hospitals Clinical Medicine Development of Special Funding (ZYLX201610) and Beijing Municipal Administration of Hospitals' Ascent Plan (DFL20151602).

\section{References}

1. Wallace MC, Preen D, Jeffrey GP and Adams LA: The evolving epidemiology of hepatocellular carcinoma: A global perspective. Expert Rev Gastroenterol Hepatol 9: 765-779, 2015.

2. Au JS and Frenette CT: Management of hepatocellular carcinoma: Current status and future directions. Gut Liver 9: 437-448, 2015.

3. Balogh J, Victor D III, Asham EH, Burroughs SG, Boktour M, Saharia A, Li X, Ghobrial RM and Monsour HP Jr: Hepatocellular carcinoma: A review. J Hepatocell Carcinoma 3: 41-53, 2016.
4. Mlynarsky L, Menachem Y and Shibolet O: Treatment of hepatocellular carcinoma: Steps forward but still a long way to go. World J Hepatol 7: 566-574, 2015.

5. Proulx CD, Holleran BJ, Lavigne P, Escher E, Guillemette G and Leduc R: Biological properties and functional determinants of the urotensin II receptor. Peptides 29: 691-699, 2008.

6. Federico A, Zappavigna S, Dallio M, Misso G, Merlino F, Loguercio C, Novellino E, Grieco P and Caraglia M: Urotensin-II receptor: A double identity receptor involved in vasoconstriction and in the development of digestive tract cancers and other tumors. Curr Cancer Drug Targets 17: 109-121, 2017.

7. Takahashi K, Totsune K, Murakami O and Shibahara S: Expression of urotensin II and urotensin II receptor mRNAs in various human tumor cell lines and secretion of urotensin II-like immunoreactivity by SW-13 adrenocortical carcinoma cells. Peptides 22: 1175-1179, 2001

8. Balakan O, Kalender ME, Suner A, Cengiz B, Oztuzcu S, Bayraktar R,Borazan E, Babacan T and Camci C: The relationship between urotensin II and its receptor and the clinicopathological parameters of breast cancer. Med Sci Monit 20: 1419-1425, 2014.

9. Wu YQ, Song Z, Zhou CH, Xing SH, Pei DS and Zheng JN: Expression of urotensin II and its receptor in human lung adenocarcinoma A549 cells and the effect of urotensin II on lung adenocarcinoma growth in vitro and in vivo. Oncol Rep 24: 1179-1184, 2010.

10. Federico A, Zappavigna S, Romano M, Grieco P, Luce A, Marra M, Gravina AG, Stiuso P, D'Armiento FP, Vitale G, et al: Urotensin-II receptor is over-expressed in colon cancer cell lines and in colon carcinoma in humans. Eur J Clin Invest 44: 285-294, 2014.

11. Wang H, Dong K, Xue X, Feng P and Wang X: Elevated expression of urotensin II and its receptor in diethylnitrosamine-mediated precancerous lesions in rat liver. Peptides 32: 382-387,2011.

12. Yu X, Wang P, Shi Z, Dong K, Feng P, Wang H and Wang X: Urotensin-II-mediated reactive oxygen species generation via NADPH oxidase pathway contributes to hepatic oval cell proliferation. PLoS One 10: e0144433, 2015.

13. Yu XT, Wang PY, Shi ZM, Dong K, Feng P, Wang HX and Wang XJ: Up-regulation of urotensin II and its receptor contributes to human hepatocellular carcinoma growth via activation of the PKC, ERK1/2, and p38 MAPK signaling pathways. Molecules 19: 20768-20779, 2014.

14. De Cobelli O, Buonerba C, Terracciano D, Bottero D, Lucarelli G, Bove $\mathrm{P}$, Altieri V, Coman $\mathrm{I}$, Perdonà $\mathrm{S}$, Facchini $\mathrm{G}$, et al: Urotensin II receptor on preoperative biopsy is associated with upstaging and upgrading in prostate cancer. Future Oncol 11: 3091-3098, 2015.

15. Grieco P, Franco R, Bozzuto G, Toccacieli L, Sgambato A, Marra M, Zappavigna S, Migaldi M, Rossi G, Striano S, et al: Urotensin II receptor predicts the clinical outcome of prostate cancer patients and is involved in the regulation of motility of prostate adenocarcinoma cells. J Cell Biochem 112: 341-353, 2011.

16. Franco R, Zappavigna S, Gigantino V, Luce A, Cantile M, Cerrone M, Facchini G, Perdonà S, Pignata S, Di Lorenzo G, et al: Urotensin II receptor determines prognosis of bladder cancer regulating cell motility/invasion. J Exp Clin Cancer Res 33: 48, 2014.

17. Harper KL, Sosa MS, Entenberg D, Hosseini H, Cheung JF, Nobre R, Avivar-Valderas A, Nagi C, Girnius N, Davis RJ, et al: Mechanism of early dissemination and metastasis in Her2 ${ }^{+}$ mammary cancer. Nature: Dec 14, 2016 (Epub ahead of print).

18. Hosseini H, Obradović MM, Hoffmann M, Harper KL, Sosa MS, Werner-Klein M, Nanduri LK, Werno C, Ehrl C, Maneck M, et al: Early dissemination seeds metastasis in breast cancer. Nature: Dec 14, 2016 (Epub ahead of print).

19. Hu Y, Yu X, Xu G and Liu S: Metastasis: An early event in cancer progression. J Cancer Res Clin Oncol 143: 745-757 2017.

20. Aufhauser DD Jr, Sadot E, Murken DR, Eddinger K, Hoteit M, Abt PL, Goldberg DS, DeMatteo RP and Levine MH: Incidence of occult intrahepatic metastasis in hepatocellular carcinoma treated with transplantation corresponds to early recurrence rates after partial hepatectomy. Ann Surg: Jan 12, 2017 (Epub ahead of print). 